\title{
Factors associated with current smoking in COPD patients: A cross-sectional study from the Eastern Black Sea region of Turkey
}

\author{
Dilek Karadogan', Ozgur Onal², Deniz Say Sahin ${ }^{3}$, Yalcın Kanbay ${ }^{4}$
}

\begin{abstract}
INTRODUCTION Even though smoking is a major reason for the development and progression of chronic obstructive pulmonary disease (COPD)-and quitting smoking is the only way to stop its progression-a significant number of smokers still continue to smoke after being diagnosed with COPD. The aim of this study is to compare the clinical and demographic characteristics of COPD patients who are current and former smokers and to find factors associated with their current smoking status.

METHODS For this study, data were collected between June 2015 and August 2016; COPD patients who had been regularly visiting Hopa State Hospital's outpatient clinic over the last year or longer were included. Their demographic, clinical and functional data were recorded. Patients completed a pulmonary function test, six-minute walk test (6-MWT), COPD assessment test (CAT), and modified Medical Research Council (mMRC) dyspnea scale. Comparisons were then made according to their smoking status.

RESULTS In total 100 patients were included in the study; with a mean age of $63.4 \pm 10.7$ years and mostly males (94\%). Regarding smoking status, $49 \%$ were current smokers and 51\% were former smokers. Multivariate logistic regression analysis revealed that current smoking was negatively associated with age (odds ratio, $\mathrm{OR}=0.93,95 \%$ confidence interval, $\mathrm{CI}=0.88-0.96)$ and Global Initiative for Chronic Obstructive Lung Disease (GOLD) stage (OR=0.32, 95\% CI $=0.13-$ 0.79 ), and was positively associated with six-minute walk distance ( $\mathrm{OR}=1.005$, 95\% $\mathrm{CI}=1.001-1.009)$ and CAT score $(\mathrm{OR}=1.07,95 \% \mathrm{CI}=1.009-1.13)$.

CONCLUSIONS Nearly half of the COPD patients in the study continued smoking even after having been diagnosed with COPD. The younger patients, with better lung function, better exercise capacity and poor quality of life were associated with current smoking.
\end{abstract}

ABBREVIATIONS COPD: Chronic obstructive pulmonary disease, CAT: COPD assessment test, mMRC: modified Medical Research Council, OR: odds ratio, Cl: confidence interval, PFT: pulmonary function test, 6-MWD: Six-minute walk distance, 6-MWT: Six-minute walk test, GOLD: Global Initiative for Chronic Obstructive Lung Disease, ATS: American thoracic society, ERS: European Respiratory Society, FEV ${ }_{1}$ : forced expiratory volume in 1 second, FVC: forced vital capacity, BMI: body mass index, SPSS: Statistical Package for the Social Sciences.

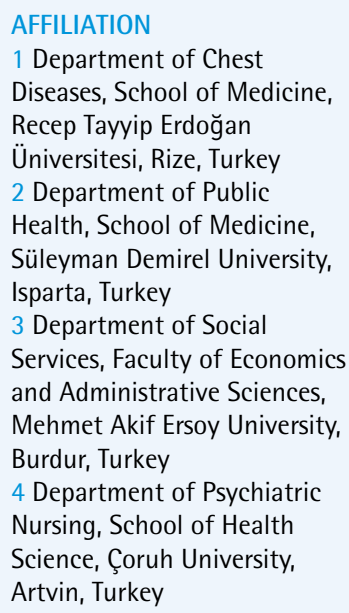

CORRESPONDENCE TO Dilek Karadogan. Department of Chest Diseases, School of Medicine, Recep Tayyip Erdoğan Üniversitesi, 05000 Rize, Turkey. E-mail: cakmakcidilek@yahoo.com

\section{KEYWORDS}

smoking, COPD, current smokers, former smokers, factors

Received: 31 October 2017 Revised: 25 March 2018 Accepted: 30 April 2018

\section{INTRODUCTION}

Chronic Obstructive Pulmonary Disease (COPD) is a major preventable and treatable public health challenge and the fourth-leading cause of death in the world. COPD is the result of cumulative exposures to particles over decades. Globally, cigarette smoking is 
the most commonly encountered risk factor for COPD; smoking cessation is the only effective treatment to stop the progression of COPD ${ }^{1}$. In a previous study, it has been determined that mild-to moderate-COPD patients who stopped smoking experienced an improvement in forced expiratory volume in 1 second $\left(\mathrm{FEV}_{1}\right)$ in the year after quitting ${ }^{2}$. However, even though smoking is the major cause of the development and progression of COPD-and quitting smoking is the only way to stop its progression-a significant number of smokers with COPD still continue to smoke after being diagnosed. In previous studies, the prevalence of current smokers was found to be higher in COPD patients compared to healthy groups ${ }^{3-5}$. Some of the reasons that have been posited to explain the higher smoking prevalence among COPD patients include: higher physical dependency upon nicotine, longer exposure time to tobacco, higher depression rate, and a higher rate of patients with lower education level. All of these factors have also been found to have a role in COPD patients' less successful quitting interventions ${ }^{6}$. However, in other studies, smokers with airway obstruction have been found to be more likely to quit smoking ${ }^{7}$.

There are also qualitative studies in the literature that evaluate the reasons why COPD patients continue to smoke ${ }^{8-10}$. Few studies, however, directly compare the demographic and functional characteristics of current and former smokers who are COPD patients ${ }^{11,12}$. Therefore, we intended to evaluate the differences between these two groups. Our study's contribution to the literature is a better understanding of the differences between smoker and former smoker COPD patients, in the interest of discovering a more effective path to encourage COPD patients to cease smoking after diagnosis.

\section{METHODS}

\section{Study population and design}

Hopa State Hospital is a secondary health-care unit in the eastern Black Sea region of Turkey. A pulmonologist, a hospital staff member, follows up COPD patients in an outpatient clinic at regular intervals-every 3 to 6 months. In this COPD outpatient clinic, each patient has a file containing their sociodemographic characteristics, disease history, physical examination results, laboratory tests results, pulmonary function test (PFT), 6-minute walk test (6-MWT) records, modified Medical Research Council dyspnea scale (mMRC), and COPD assessment test (CAT) scores. There were 117 patients having regular follow-ups in the COPD outpatient clinic at the time of the study. During visits, appropriate patients who wanted to join the study were included after giving written informed consent. Inclusion criteria were: a) patients who had received a COPD diagnosis at least one year ago according to GOLD guidelines 1 and had regularly attended their control visits at the COPD outpatient clinic during the last year; b) patients who were in a stable period of the illness ${ }^{1}$; c) patients who could undergo the PFT, 6-MWT, mMRC and CAT tests; and d) patients who were current smokers at the time of their initial COPD diagnosis.

The exclusion criteria were: a) patients who were evaluated to be in the COPD exacerbation period according to Global Initiative for Chronic Obstructive Lung Disease (GOLD) guidelines 1; b) patients who did not want to join the study; c) patients who could not complete the PFT and the questionnaires; d) patients with cognitive disorders due to diseases like dementia, Parkinson's disease or schizophrenia; e) patients with a walking disability due to any orthopedic or neurological diseases; and f) patients with higher scores in the Beck anxiety scale $(\geqslant 8)$ and/or Beck depression scale $(\geqslant 10)$.

Each of the patients who had quit smoking after the COPD diagnosis had done it on their own without using smoking cessation medications. All of them reported that they had received advice from their doctor to quit and had been informed about the harmful effects of smoking on their lung health.

\section{Ethics approval, consent to participate and data collection}

Before starting the study, ethics approval (3 July 2015) was received from the Ethics Committee of the Rectorship, Artvin Çoruh University. Permission for the study was also obtained from Artvin Government Hospital's general secretary. Written informed consent forms of the participants were obtained by the first author of the study. Afterwards, data collection started in June 2015 and ended August 2016. In the first part of the study, the researchers used face-to-face interviewing of patients by the pulmonologist to obtain information about their age, 
sex, education level, current work status, smoking status, comorbid diseases, COPD diagnosis time, number of exacerbations and hospitalizations due to COPD in the last year, answers to mMRC dyspnea scale $^{13}$, and $\mathrm{CAT}^{14}$.

In the second part of the research, participants' height and weight were measured wearing light clothes, no hat or shoes, by the PFT technician nurse ${ }^{15,16}$. The 6 -MWT ${ }^{17}$ and PFT were performed by the same trained nurse.

\section{Questionnaire}

The CAT is a short, specific quality of life (QoL) questionnaire for measuring the impact of COPD on a patient's well-being and daily life. It consists of eight items evaluating the frequency of cough, phlegm, chest tightness, breathless level at exercise, sleep status, and energy status, with scores ranging from 0 to 5 (0-no impairment, 5-greatest impairment). An overall score is calculated by adding the score from each item, with total scores ranging from 0 to 40 , the higher scores indicating more severe health status impairment or a poorer control of COPD ${ }^{14}$. We used a Turkish version of the CAT that has already been translated and validated for use ${ }^{18}$.

\section{Functional assessment}

PFT: The lung function test was performed in a seated position using a Spirovit SP-260 spirometer (Schiller Medical, Moscow, Russia) consistent with American Thoracic Society (ATS)/European Respiratory Society (ERS) guidelines. Forced vital capacity (FVG), $\mathrm{FEV}_{1}$ and $\mathrm{FEV}_{1} / \mathrm{FVG}$ rate were recorded. Lung function test parameters were expressed as a percentage of the predicted values for age, height, body weight, and sex ${ }^{15,16}$.

6-MWD: This was performed according to ATS guidelines ${ }^{17}$. Patients were asked to walk quickly along a 30 metre level corridor for 6 minutes, and the total distance walked was recorded in metres. The test was carried out twice with a 30 -minute interval. The best value of the two tests was used for statistical analysis. Heart rate and oxygen saturation were recorded during the 6 -MWD using a pulse oximeter (PlusMED, plus-50DL, Turkey).

\section{Information on potential confounders}

Smoking status was recorded as former smoker or current smoker. Anyone who had smoked more than 100 cigarettes in their lifetime and smoked in the last 28 days was classified as a current smoker; someone who had smoked more than 100 cigarettes in their lifetime but had not smoked in the last 28 days was classified as a former smoker ${ }^{19}$. Number of packyears (packs smoked per day $\times$ years as a smoker) was also recorded. A history of comorbid disease was defined as a positive answer to questions regarding physician-diagnosed: diabetes, hypertension, cerebrovascular disease, pulmonary disease, ischemic heart disease, and other diseases. Employment status was asked of each patient, and at the time of data analysis categorized as retired or working actively. Body mass index (BMI) was calculated as weight $(\mathrm{kg})$ divided by height $(\mathrm{m})$ squared. COPD exacerbations and hospital-treated COPD exacerbations in the last year were included in patient interviews, and also checked through the recorded hospital database. GOLD stage 1-4 and GOLD category (A, B, C, D) were recorded according to GOLD guidelines ${ }^{1}$.

\section{Statistical analysis}

Data were analyzed using Statistical Package for the Social Sciences version 20. First, descriptive analysis (mean, proportions) was performed for each dependent variable. Categorical variables were described using their absolute and relative frequencies, while quantitative variables were described by the mean and standard deviation. To evaluate the relationship between independent and dependent categorical variables, Pearson's chi-squared test or the Fisher exact test was used; for numerical variables an independent sample t-test was used. The associations were considered significant at $\mathrm{p}<0.05$. Odds ratio $(\mathrm{OR})$ univariates were calculated by logistic regression to evaluate the different risks contemplated in the study, including all demographic, clinical and quality-oflife variables. After backward analysis, the various adjusted ORs were calculated using multivariate logistic regression, and only statistically significant associations are shown in Table 1.

\section{RESULTS}

In total 100 patients were included in the study; mean age of the patients was $63.4 \pm 10.7$ years and $94 \%$ of patients were male. Most of the patients 
Table 1. Factors associated with current smoking in univariate and multivariate analysis. Hopa State Hospital, $2015-2016(n=100)$

\begin{tabular}{|c|c|c|c|c|c|c|}
\hline & \multicolumn{3}{|c|}{ Univariate Analysis } & \multicolumn{3}{|c|}{ Multivariate Analysis } \\
\hline & OR & $95 \% \mathrm{CI}$ & $p$ & OR & $95^{\circ} \circ \mathrm{CI}$ & $p$ \\
\hline Age (per 1-year increment) & 0.93 & $0.89-0.97$ & 0.001 & 0.93 & $0.88-0.96$ & 0.009 \\
\hline Employment status (working actively) & 3.21 & $1.28-8.06$ & 0.013 & & & \\
\hline $\begin{array}{l}\text { Hospitalization in last year (per } 1 \text { number } \\
\text { increment) }\end{array}$ & 0.66 & $0.48-0.90$ & 0.01 & & & \\
\hline FEV1\% (per 1\% increase) & 1.03 & $1.00-1.06$ & 0.009 & & & \\
\hline FVC\% (per 1\% increase) & 1.03 & $1.01-1.05$ & 0.004 & & & \\
\hline GOLD stage (per 1 stage increment) & 0.42 & $0.21-0.81$ & 0.01 & 0.32 & $0.13-0.79$ & 0.013 \\
\hline 6-MWD (per $1 \mathrm{~m}$ increase) & 1.00 & $1.00-1.00$ & 0.001 & 1.005 & $1.001-1.009$ & 0.02 \\
\hline MMRC (per 1 stage increase) & 0.63 & $0.45-0.90$ & 0.01 & & & \\
\hline CAT (per 1 stage increase) & 1.00 & $0.96-1.04$ & 0.88 & 1.07 & $1.009-1.13$ & 0.02 \\
\hline COPD category (per 1 category increase) & 0.27 & $0.12-0.64$ & 0.003 & & & \\
\hline Disease duration (per 1 year increase) & 0.92 & $0.86-0.98$ & 0.02 & & & \\
\hline Number of COPD medications & 0.63 & $0.43-0.94$ & 0.02 & & & \\
\hline
\end{tabular}

(per 1 medication increase)

Values are expressed as odds ratio (OR) and confidence interval (CI). Multivariate analysis was controlled for age, employment status, hospitalization number, FEV1\% predicted, $\mathrm{FVC} \%$ predicted, GOLD stage, 6-MWD, mMRC score, CAT score, COPD category, disease duration and number of COPD medications.

had graduated from primary school $(72 \%)$, were retired ( $71 \%$ ), were in GOLD stage 2 or $3(36 \%$ and $54 \%$, respectively), had an mMRC dyspnea score of 2 or higher $(67 \%)$, and had a high $(\geqslant 10)$ CAT score $(87 \%)$. Of the participants, $49 \%$ were current smokers. Detailed characteristics of the patients and the comparisons according to their smoking status are seen in Table 2.

In univariate analysis, current smoking was negatively associated with age $(p=0.001)$, GOLD stage $(p=0.01)$, COPD category $(p=0.003)$, number of hospitalizations $(\mathrm{p}=0.01)$, mMRC dyspnea score $(p=0.01)$, disease duration $(p=0.02)$, and number of COPD medications $(p=0.02)$. Current smoking was positively associated with $\mathrm{FEV}_{1} \%$ predicted $(\mathrm{p}=0.009)$, FVC $\%$ predicted $(\mathrm{p}=0.004)$, and 6-MWD $(\mathrm{p}=0.001)$. However, in multivariate analysis, current smoking was negatively associated with age $(\mathrm{OR}=0.93,95 \% \mathrm{CI}=0.88-0.96, \mathrm{p}=0.009)$ and GOLD stage $(\mathrm{OR}=0.32,95 \% \mathrm{CI}=0.13-0.79$, $\mathrm{p}=0.013)$, and was positively associated with 6-MWD $(\mathrm{OR}=1.005,95 \% \mathrm{CI}=1.001-1.009, \mathrm{p}=0.02)$ and CAT score $(\mathrm{OR}=1.07,95 \% \mathrm{CI}=1.009-1.13$, $\mathrm{p}=0.02)($ Table 1).

Table 2. Characteristics of patients according to their cigarette smoking status; Hopa State Hospital, $2015-2016$ $(n=100)$

\begin{tabular}{|c|c|c|c|}
\hline & $\begin{array}{l}\text { All patients } \\
100\end{array}$ & $\begin{array}{l}\text { Current smokers } \\
19\end{array}$ & $\begin{array}{l}\text { Former smokers } \\
51\end{array}$ \\
\hline Age (mean \pm SD) & $63.4 \pm 10.7(\min 40-\max 85)$ & $59.6 \pm 9.1^{*}$ & $67.0 \pm 10.9$ \\
\hline \multicolumn{4}{|l|}{ Sex } \\
\hline Male $(n, \%)$ & $94(94 \%)$ & $47(95.9 \%)$ & $47(92.2 \%)$ \\
\hline Female & $6(6 \%)$ & $2(4.1 \%)$ & $4(7.8 \%)$ \\
\hline \multicolumn{4}{|l|}{ Education level } \\
\hline 0 & $2(2 \%)$ & $1(2.04 \%)$ & $1(1.96 \%)$ \\
\hline 5 year primary schooling & $72(72 \%)$ & $32(65.3 \%)$ & $40(78.4 \%)$ \\
\hline 8 years secondary schooling & $8(8 \%)$ & $4(8.1 \%)$ & $4(7.8 \%)$ \\
\hline 11 years high schooling & $13(13 \%)$ & $8(16.3 \%)$ & $5(9.8 \%)$ \\
\hline 15 years university & $5(5 \%)$ & $4(8.1 \%)$ & $1(1.96 \%)$ \\
\hline
\end{tabular}


Table 2. continued

\section{III patients}

\section{Work status}

Actively working

Retired

Smoking (pack/year)

COPD diagnosis age (mean)

Disease duration (mean $\pm \mathrm{SD}$ )

BMI $\left(\mathrm{kg} / \mathrm{m}^{2}\right)\left(\right.$ mean $\left._{ \pm} \mathrm{SD}\right)$

Number of exacerbations in last 1 year $\left(\right.$ mean $\left._{ \pm} \mathrm{SD}\right)$

0

1

2-5

$>5$

Number of hospital-treated exacerbations

(emergency+admission)

0

$\geq 1$

$\mathrm{FEV}_{1} \%\left(\right.$ mean $\left._{ \pm} \mathrm{SD}\right)$

$\mathrm{FVC} \%$

$\mathrm{FEV}_{1} / \mathrm{FVC}$

GOLD stage

1

2

3

4

6-MWD (mean \pm SD) in metres

MMRC dyspnea score (Mean \pm SD)

$<2$

$\geq 2$

CAT $($ mean $\pm S D)$

$<10$

$\geq 10$

\section{COPD category}

A

B

C

D

Number of patients with LTOT

Number of COPD medications (mean \pm SD)

Number of comorbidities 100

Current smokers Former smokers 19 51

$20(40.8 \%)^{*}$

$9(17.6 \%)$

$29(59.1 \%)$

$42(82.3 \%)$

$44.2 \pm 16.2(\min 20-\max 100)$

$43.5 \pm 13.9$

$44.9 \pm 18.2$

$56.1 \pm 10.3$

$54.3 \pm 8.7$

$57.9 \pm 11.4$

$7.2 \pm 7.7$

$5.30 \pm 5.54^{*}$

$9.09 \pm 8.98$

$26.4 \pm 5.9$

$2.52 \pm 2.53$

$26.1 \pm 5.74$

$26.6 \pm 6.16$

$2.18 \pm 1.99$

$2.84 \pm 2.94$

$8(16.3 \%)$

$6(11.7 \%)$

30 (30\%)

14 (28.5\%)

$16(31.3 \%)$

23 (46.9\%)

23 (45.0\%)

4 (8.1\%)

$6(11.7 \%)$

$0.67 \pm 1.04^{*}$

$1.58 \pm 2.04$

$1.14 \pm 1.68$

$31(63.2 \%)^{*}$

20 (39.2\%)

51 (51\%)

18 (36.7\%)

31 (60.7\%)

$53.6 \pm 17.0^{*}$

$45.1 \pm 13.3$

$49.3 \pm 15.7$

$62.4 \pm 21.3$

$70.5 \pm 23.3^{*}$

$55.5 \pm 16.8$

$60.0 \pm 8.26$

$59.9 \pm 9.66$

$60.0 \pm 6.97$

$5(5 \%)$
$36(36 \%)$
$54(54 \%)$
$5(5 \%)$
$335.5 \pm 120$
$2.2 \pm 1.2$
$33(33 \%)$
$67(67 \%)$
$19.4 \pm 9.1$
$15(15 \%)$
$85(85 \%)$

$4(8.1 \%)$

$1(1.9 \%)$

23 (46.9\%)

13 (25.4\%)

$34(66.6 \%)^{*}$

3 (5.8\%)

2 (4.08\%)

$289.9 \pm 101.1$

$2.54 \pm 1.17$

$1.91 \pm 1.18$

$14(27.4 \%)$

19 (38.7\%)

37 (72.5\%)

30 (61.2\%)

$19.3 \pm 9.15$

$6(11.7 \%)$

9 (19.5\%)

45 (88.2\%)

$40(81.6 \%)$

$3(5.8 \%)$

$11(11 \%)$

$8(16.3 \%)^{*}$

11 (21.5\%)

$5(5 \%)$

19 (38.7\%)

$5(9.8 \%)$

54 (54\%)

0

32 (62.7\%)

$10(10 \%)$

22 (44.8\%)

8 (15.6\%)

$3.09 \pm 1.07$

$2(4.08 \%)$

$3.33 \pm 0.99$

$0.46 \pm 0.64$

$2.84 \pm 1.10^{*}$

$0.57 \pm 0.70$

Column percentages are given

Values are expressed as mean (SD) and frequency (\%). ${ }^{*} p$-value $<0.05$ compares current smoker and former smoker patients.

CAT: COPD assessment test; FEV : forced expiratory volume in 1 second; FVC: forced vital capacity; SD: standard deviation; BMI: body mass index; 6-MWD: 6-min walking distance (m); mMRC: modified Medical Research Council dyspnea scale; LTOT: long-term oxygen therapy. 


\section{DISCUSSION}

Our findings showed that among COPD patients, current smokers were more likely to be younger, have better lung function, walk a longer 6-MWD, and conversely, have worse quality of life, detected by the higher scores in the CAT, compared to former smokers.

Previous studies around the world have shown that among COPD patients, current smokers' prevalence is between $33.6 \%$ and $47.2 \%^{3-5,11,12,20}$. Moreover, current smoking prevalence has been found to be higher among COPD patients compared to healthy individuals in previous international studies ${ }^{3,5}$. Similarly, in this study we found COPD patients' current smoking rate to be $49 \%$ (50\% among males and $33.3 \%$ among females), while the general recent smoking prevalence among individuals older than 40 years in Turkey is approximately $40 \%$ among men and $13 \%$ among women ${ }^{21}$. While there has been a decrease in the population's current smoking prevalence compared to previous years ${ }^{21}$, according to our findings there was no decrease among COPD patients' current smoking prevalence compared with previous national studies ${ }^{22,23}$. Turkish COPD patients' smoking prevalence is estimated to be approximately $60 \%$.

One interesting indicator was that while lung function and mobility/endurance were relatively unaffected in COPD patients who continued to smoke, potentially because of their youth or shorter smoking time, quality of life was still significantly lower-yet not low enough to have an apparent impact on motivation to quit. It is essential to find solutions for successful cessation interventions for patients in this group, because smokers with COPD are shown to be less successful in quitting ${ }^{24}$. Though there are various reasons cited for this trend $\mathrm{d}^{3,25}$, in previous studies of COPD patients those who were able to quit were found to be older ${ }^{26}$ and have a further advanced disease ${ }^{11}$. Furthermore, patients who are beginning to lose the ability to take part in certain activities are more likely to quit, most likely in an effort to regain those abilities ${ }^{4}$. In other words, current smokers are living with less severe COPD-related activity limitations, and so their perception of COPD may be different from those with more severe symptoms. At diagnosis, more intensive education should be given to COPD patients, not only about inhaler use but also about outcomes and systemic effects of COPD, and the importance of quitting smoking and avoiding secondhand smoke exposure as well. At that point, brief interventions including our results could be an effective way to encourage smoking cessation in newly diagnosed, young COPD patients at the earlier stages of the disease ${ }^{27}$. Particularly, pointing out the increased respiratory symptoms and lowered QoL-even compared to older, more severe COPD patients who no longer smoke-could be the key. Patients should be supported in their quit attempts not only with motivational counselling but also with changes in tobacco control policies, such as covering smoking cessation interventions and approved SC medications under health insurance, as recommended in a previous guidance ${ }^{28}$. COPD patients demonstrate proven cost-effectiveness of free SC interventions, and they need support to overcome nicotine withdrawal symptoms and other challenges is smoking cessation ${ }^{29-31}$.

Most qualitative studies evaluating reasons for continued smoking in COPD patients found that cigarettes are regarded like friends. For other patients, quitting smoking after diagnosis was considered useless and too late to make a difference, even though they were aware that their COPD was caused and exacerbated by smoking ${ }^{9,32}$. In this study, we even verified that all of the patients were aware that the main reason for the development of their illness was smoking, because they had been followed-up with and educated about the illness in the COPD outpatient's clinic. However, we did not obtain qualitative information about their reasoning for continuing to smoke. To our knowledge there is no qualitative study that evaluates Turkish COPD patients' smoking status. Learning the reasons why patients believe they still can continue to smoke would be important to discern and so better manage their quit attempts.

Our study showed that higher CAT scores were associated with current smoking. Similarly, Cheruvu et al. ${ }^{12}$ found their current smoker COPD patients' health-related quality of life to be worse than former smokers, regardless of their younger mean age or disease severity. CAT score can change or improve via many factors, including smoking cessation and pulmonary rehabilitation ${ }^{33}$. In a recent study, a group of smoker COPD patients' CAT scores 
decreased from $18.9 \pm 7.3$ to $8.1 \pm 6.1$ six months after quitting smoking ${ }^{34}$. This is an important point for smoker COPD patients to understand, and that they can expect an improvement in QoL after quitting smoking, which should motivate them in their quit attempts. Explaining and comparing QoL should be an integral part of COPD diagnosis and education.

Only 100 participants were found who were both current patients at the clinic and met the inclusion criteria. The clinic/hospital was located in a small town. Furthermore, many patients did followups with their own internal medicine specialists or family doctors. As a result, not all of the local COPD patients apply to the pulmonology outpatient clinic. That may explain the low number of the study population, as the methodology of face-toface interviews required convenience sampling. We did not use any biological confirmation of smoking status, instead grouping according to patient report. This is one of the limitations of the study. But it has been shown that smokers with COPD do report their smoking status reliably ${ }^{35}$. The evaluation of comorbid diseases also depended on the patients' self-report; we did not do additional tests to evaluate the comorbid diseases. This may have lowered the prevalence of comorbid disease in the study; it has been reported that comorbidity prevalence and detection rates can be variable due to the research method used and style of questioning ${ }^{36}$. We asked our patients: 'Do you have any other diseases, such as cardiac disease, diabetes, hypertension?'. Therefore, most of the reported comorbidities included were from those systems. Other less severe diseases may not have been reported by the patient. Another limitation is that we could not be sure whether former smokers quit when their disease was at its early stages. It was not possible to evaluate former smokers' functional capacity and COPD clinical status at the time of their successful quitting intervention.

\section{CONCLUSIONS}

According to this study, nearly half of COPD patients continued to smoke even after they had been diagnosed with COPD. Among them, those who were younger, were at the early stages of the disease, and had better performance status on the walk test, were more likely to continue to smoke. To determine the reasons behind these results, qualitative studies, which are extremely rare in our country, are needed to evaluate the underlying reasons of COPD patients' smoking status. The fourth factor, lower QoL, may not explain reasons for continued smoking but instead be a valuable reference to discourage it after diagnosis.

\section{REFERENCES}

1. Global Initiative for Chronic Obstructive Lung Disease. Global strategy for the diagnosis, management, and prevention of Chronic Obstructive Pulmonary Disease. Published, 2016. Accessed October 31, 2017.

2. Scanlon PD, Connett JE, Waller LA, et al. Smoking cessation and lung function in mild-to-moderate Chronic Obstructive Pulmonary Disease. The Lung Health Study. Am J Respir Crit Care Med. 2000;161(2 Pt 1):381-390. doi:10.1164/ajrccm.161.2.9901044

3. Shahab L, Jarvis MJ, Britton J, West R. Prevalence, diagnosis and relation to tobacco dependence of chronic obstructive pulmonary disease in a nationally representative population sample. Thorax. 2006;61(12):1043-1047. doi:10.1136/thx.2006.064410

4. Schiller JS, Ni H. Cigarette smoking and smoking cessation among persons with chronic obstructive pulmonary disease. Am J Health Promot. 2006;20(5):319323. doi:10.4278/0890-1171-20.5.319

5. Schauer GL, Wheaton AG, Malarcher AM, Croft JB. Smoking prevalence and cessation characteristics among U.S. adults with and without COPD: findings from the 2011 Behavioral Risk Factor Surveillance System. COPD. 2014;11(6):697-704. doi:10.3109/15412555.2014.898049

6. Jiménez Ruiz CA, Ramos Pinedo A, Cicero Guerrero A, Mayayo Ulibarri M, Cristobal Fernández M, Lopez Gonzalez G. Characteristics of COPD smokers and effectiveness and safety of smoking cessation medications. Nicotine Tob Res. 2012;14(9):1035-1039. doi:10.1093/ntr/nts001

7. Bednarek M, Gorecka D, Wielgomas J, et al. Smokers with airway obstruction are more likely to quit smoking. Thorax. 2006;61(10):869-873. doi:10.1136/thx.2006.059071

8. Eklund BM, Nilsson S, Hedman L, Lindberg I. Why do smokers diagnosed with COPD not quit smoking? - a qualitative study. Tob Induc Dis. 2012;10(1):17. doi:10.1186/1617-9625-10-17

9. Poureslami I, Shum J, FitzGerald JM. Why do Chinese people with COPD continue smoking: the attitudes and beliefs of Chinese residents of Vancouver, Canada. Diversity and Equality in Health and Care. 2015;12(1):18-27. doi:10.21767/2049-5471.100025

10. Bestall J, Paul E, Garrod R, Garnham R, Jones P, Wedzicha J. Usefulness of the Medical Research Council (MRC) dyspnoea scale as a measure of disability in 
patients with chronic obstructive pulmonary disease. Thorax. 1999;54(7):581-586. doi:10.1136/thx.54.7.581

11. Kupiainen H, Kinnula VL, Lindqvist A, et al. Successful Smoking Cessation in COPD: Association with Comorbidities and Mortality. Pulm Med. 2012;2012:725024. doi:10.1155/2012/725024

12. Cheruvu VK, Odhiambo LA, Mowls DS, Zullo MD, Gudina AT. Health-related quality of life in current smokers with COPD: factors associated with current smoking and new insights into sex differences. Int J Chron Obstruct Pulmon Dis. 2016;11:2211-2219. doi:10.2147/copd.s106207

13. Bestall J, Paul E, Garrod R, Garnham R, Jones P, Wedzicha J. Usefulness of the Medical Research Council (MRC) dyspnoea scale as a measure of disability in patients with chronic obstructive pulmonary disease. Thorax. 1999;54(7):581-586. doi:10.1136/thx.54.7.581

14. Jones PW, Harding G, Berry P, Wiklund I, Chen WH, Kline Leidy N. Development and first validation of the COPD Assessment Test. Eur Respir J. 2009;34(3):648654. doi:10.1183/09031936.00102509

15. Pellegrino R, Viegi G, Brusasco V, et al. Interpretative strategies for lung function tests. Eur Respir J. 2005;26:948-968. doi:10.1183/09031936.05.00035205

16. Miller MR, Crapo R, Hankinson J, et al; General considerations for lung function testing. Eur Respir J. 2005;26:153-161. doi:10.1183/09031936.05.00034505

17. ATS Committee on Proficiency Standards for Clinical Pulmonary Function Laboratories. ATS statement: guidelines for the six-minute walk test. Am J Respir Crit Care Med. 2002;166:111-117. doi:10.1164/rccm.166/1/111

18. Yorgancıoğlu A, Polatlı M, Aydemir Ö, et al. Reliability and validity of Turkish version of COPD assessment test. Tuberk Toraks. 2012;60(4):314-320. doi: $10.5578 / \mathrm{tt} .4321$

19. Definitions of smoking status. http://www.health.govt. nz/our-work/preventative-health-wellness/tobaccocontrol/tobacco-control-guidance-practitioners/ definitions-smoking-status. Accessed October 31, 2017.

20. Au DH, Bryson CL, Chien JW, et al. The effects of smoking cessation on the risk of chronic obstructive pulmonary disease exacerbations. J Gen Intern Med. 2009;24(4):457-463. doi: 10.1007/s11606-009-0907-y.

21. Public Health Institution of Turkey. Global Adult Tobacco Survey 2012. http://www.who.int/tobacco/ surveillance/survey/gats/report_tur_2012.pdf?ua $=1$. Published, 2014. Accessed October 31, 2017.

22. Bülbül Y, Öztuna F, Gülsoy A, Özlü T. Chronic Obstructive Pulmonary Disease in Eastern Black Sea Region: Characteristics of the Disease and the Frequency of Influenza-Pneumococcal Vaccination. Turkiye Klinikleri J Med Sci. 2010;30(1):24-29. doi:10.5336/medsci.2008-8763

23. Gunen H, Hacievliyagil SS, Kosar F, et al. Factors affecting survival of hospitalised patients with COPD. Eur Respir J. 2005;26(2):234-241. doi:10.1183/09031936.05.00024804

24. Tashkin DP, Murray RP. Smoking cessation in chronic obstructive pulmonary disease. Respir Med. 2009;103(7):963-974. doi:10.1016/j.rmed.2009.02.013

25. Jiménez-Ruiz CA, Masa F, Miravitlles M, et al. Smoking characteristics: differences in attitudes and dependence between healthy smokers and smokers with COPD. Chest. 2001;119(5):1365-1370. doi:10.1378/chest.119.5.1365

26. Adams SG, Pugh JA, Kazis LE, Lee S, Anzueto A. Characteristics associated with sustained abstinence from smoking among patients with COPD. Am J Med. 2006;119(5):441-447. doi:10.1016/j.amjmed.2005.09.055

27. World Health Organization. Toolkit for delivering the 5A's and 5R's brief tobacco interventions in primary care. Geneva, Switzerland: World Health Organization; 2014.

28. McAfee T, Babb S, McNabb S, Fiore MC. Helping smokers quit - opportunities created by the Affordable Care Act. N Engl J Med. 2015;372(1):5-7. doi:10.1056/NEJMp1411437

29. Christenhusz LC, Prenger R, Pieterse ME, Seydel ER, van der Palen J. Cost-effectiveness of an intensive smoking cessation intervention for COPD outpatients. Nicotine Tob Res. 2012;14(6):657-663. doi:10.1093/ntr/ntr263

30. Jiménez-Ruiz CA, Solano-Reina S, Signes-Costa J, et al. Budgetary impact analysis on funding smokingcessation drugs in patients with COPD in Spain. Int J Chron Obstruct Pulmon Dis. 2015;10:2027-2036. doi:10.2147/COPD.S87597

31. Tashkin DP. Smoking Cessation in Chronic Obstructive Pulmonary Disease. Semin Respir Crit Care Med. 2015;36(4):491-507. doi:10.1055/s-0035-1555610

32. Wilson JS, Elborn JS, Fitzsimons D. 'It's not worth stopping now': why do smokers with chronic obstructive pulmonary disease continue to smoke? A qualitative study. J Clin Nurs. 2011;20(5-6):819-827. doi:10.1111/j.1365-2702.2010.03319.x

33. Postolache P, Nemeș RM, Petrescu O, Merișanu IO. Smoking cessation, pulmonary rehabilitation and quality of life at smokers with COPD. Rev Med Chir Soc Med Nat Iasi. 2015;119(1):77-80.

34. Jimenez-Ruiz CA, Pascual Lledó JF, Cícero Guerrero A, Cristóbal Fernández M, Mayayo Ulibarri M, Villar Laguna C. Analysis of quality of life in patients with Chronic Obstructive Pulmonary Disorder (COPD) who give up smoking. Semergen. 2017:1138-3593(17)30231-9. doi:10.1016/j.semerg.2017.08.003

35. Wilson JS, Elborn JS, Fitzsimons D, McCrumGardner E. Do smokers with chronic obstructive pulmonary disease report their smoking status reliably? A comparison of self-report and bio-chemical validation. Int J Nurs Stud. 2011;48(7):856-862. doi:10.1016/j.ijnurstu.2011.01.002

36. Lucke T, Herrera R, Wacker M, et al. Systematic Analysis of Self-Reported Comorbidities in Large Cohort 
Studies - A Novel Stepwise Approach by Evaluation of Medication. PLoS One. 2016;11(10):e0163408.

doi:10.1371/journal.pone.0163408

ACKNOWLEDGEMENTS

We would like to thank Dr. Marc Miravitlles for his excellent supervision and comments on the study and Laura Paquette for her input and guidance in the written development of this work.

CONFLICTS OF INTEREST Authors have completed and submitted the ICMJE Form for Disclosure of Potential Conflicts of Interest and none was reported.

FUNDING

There was no source of funding for this research.

PROVENANCE AND PEER REVIEW

Not commissioned; externally peer reviewed 